\title{
Synthesis and characterization of copoly(L-lactic acid-caprolactone) and its stereo-effect with poly D-lactic acid and biodegradability
}

\author{
M. Amirul Hoque ${ }^{a *}$, A. Nakayama ${ }^{b}$, H. P. Nur ${ }^{a}$, S. K. Ray ${ }^{a}$, M. M. Rahman ${ }^{a}$ and S. Khabir-Uddina, \\ ${ }^{a}$ Bangladesh Council of Scientific and Industrial Research (BCSIR), Dhanmondi, Dhaka-1205 and \\ ${ }^{b}$ Advanced Industrial Science and Technology, Midorigaoka, Ikeda, Osaka, Japan
}

\begin{abstract}
Random copolymerizations of L-Lactide with $\varepsilon$-Caprolactone by ring opening polymerization reactions were carried out. A number of copolymers were formed and observed that any composition of copolymer can be formed by changing the feed ratio of the respective monomers. The effect of temperature and time in copolymerization reaction were studied. For their characterization, NMR, IR, DSC and GPC were measured. The stereo-effect of the lactic acid based biodegradable polymers and copolymers for improve thermo-mechanical properties were studied. The obtained copolymers also show stereo-effect like homopolymer. The biodegradability of obtained polymers, copolymers and stereocomplex were studied in three different biodegradation methods; e.g., Enzymatic method, Composting method and Activated Sludge treatment method; and compared to each other.
\end{abstract}

Key words : Random copolymerizations, Ring opening polymerization, Stereo-effect, Biodegradability

\section{Introduction}

Plastic is the most extensively used polymer in the world. Plastics are used extensively in packaging due to their outstanding physical, mechanical, and chemical properties (Hernandez, 2004). It is impossible to develop modern civilization without plastic. Almost all commercial products must be packaged in plastic (Kelly, 1997). Because plastic packaging provides excellent protection of the product (Sinclair, 1995); it is almost nonreactive, it prevents products from air and moisture, it is very cheap to manufacture and it seems to last for a long time. Lasting for a long time, however, is now creating a major environmental problem after depositing in the atmosphere (Maneka Gandi, 2010). Another problem is that the traditional plastics are manufactured from non-renewable resources such as mineral oil, coal and natural gas, which enhances global warming (Bruno Gervet, 2007). Plastic Waste is more dangerous than Global Warming (Blair Coursey, 2003).

At present, biobased biodegradable polymers are the demand of times (Leaversuch, 2002). Among all the biobased biodegradable polymers, PLLA (poly L-lactic acid) is the most common and most widely used polymer because of its ease of preparation and excellent physical and mechanical properties (Luc Averous, 2009).

It is thought to be key component for the replacement of petrochemical based polymer products. Hence, a lot of experiments on this polymer already have been done (Yoshiharu Kimura, 2009; Courgneau, 2004). But still the polymer has some limitations in its mechanical and thermal properties; which are as- the mechanical properties, it has strong tensile strength value but the elongation at break is much smaller, and its resistance to heat is often around $100^{\circ} \mathrm{C}$ in-spite of its high melting temperature $\left(178^{\circ} \mathrm{C}\right)$ (Kawasaki, 1998). Moreover, PLLA is well known for its biodegradability (Avella, 2001; Karlsson, 1998), but its lackadaisical biodegradation is hard to deal. To improve its brittle properties and biodegradability, random copolymerization is one of the expected approaches (Kylma, 1997), and lots of comonomers Lactones, Glycidol, etc. are being studied. Suppression of crystallinity results in flexible properties and excellent biodegradation (Fritz, 2001). Implementation of additives is also a good approach in this regards (Nadia Ljungberg, 2003; Ljungberg, 2005). 
In this experiment, we have synthesized some copolymer of L-Lactic acid and $\varepsilon$-Caprolactone at different ratio; studied the thermal and mechanical properties of the copolymers and also studied the effect of their stereocomplex with poly D-lactic acid and their Biodegradation in different medium e.g., Composting, Enzymatic and Activated Sludge treatment method.

\section{Materials and Methods}

Synthesis of polymers from the monomers D-lactide, L-lactide and $\varepsilon$-Caprolactone and copolymers of L-lactide and $\varepsilon$-Caprolactone of different compositions were carried out in the presence of tetraphenyl tin as an initiator.

\section{Reagents}

L-lactide (LLA) and D-lactide (DLA) were purified by recrystallization from dried toluene under nitrogen atmosphere and then dried for $24 \mathrm{~h}$ under vacuum at $30^{\circ} \mathrm{C}$. $\varepsilon$-Caprolactone (CL) (Boehringer Ingelheim) was purified by distillation under reduced pressure and treated with sodium sulfate to remove any residual moisture traces. Tetraphenyl tin and magnesium ethoxide (Wako Chemicals, Japan) was used as an initiator without purification. The enzymes for the biodegradation tests were Proteinase-K, Standard Activated Sludge provided from National Inst. Tech. Eval., Japan and compost from (Natural Compost Ltd.) were collected and used directly after checking moisture content.

\section{Synthesis}

The polymers and copolymers were synthesized from their respective monomers. The polymerization reaction was carried out with L-lactide and $\varepsilon$-Caprolactone monomers (Kawasaki, 1998; Nijenhuis, 1992; Tasaka, 2001). The monomers/comonomers and tetraphenyl tin initiator $(0.3$ mol\% versus total monomers) were charged on a dried two necked flask. The flask was sealed with air condenser and moisture trap and heated at $130 \pm 10^{\circ} \mathrm{C}$ for 3 days. They were allowed to cool down to room temperature and the contents were dissolved in chloroform after the addition of a few drops of methanol to stop the polymerization reaction. Some of the crude polymer was obtained as a precipitate in excess methanol, and was purified by repeated precipitations. Then they were dried in a vacuum dryer at $50^{\circ} \mathrm{C}$ for $24 \mathrm{~h}$. A series of copolymers with different compositions were synthesized by changing the feed molar ratio of LLA/CL from $0 / 100$ to $100 / 0$.

\section{Measurement}

\section{Nuclear magnetic resonance spectroscopy}

${ }^{1} \mathrm{H}$ NMR $(500 \mathrm{MHz})$ and ${ }^{13} \mathrm{C}$ NMR $(125 \mathrm{MHz})$ spectra were recorded on a JEOL JNM A-500 spectrometer. The spectra were mainly obtained chloroform-d solutions at room temperature with tetramethylsilane (TMS) as internal standard (Espartero, 1996).

\section{Fourier-transform infra-red spectroscopy}

The Infrared (IR) spectra were recorded on a Nicolet 710 FTIR spectrometer. The samples were recorded using films casted on a potassium chloride plate from chloroform solutions (Kawasaki, 1998).

\section{Gel permeation chromatography}

The molecular-weight distributions $\left(\mathrm{M}_{\mathrm{n}}, \mathrm{M}_{\mathrm{w}}\right.$ and polydispersity indices) were measured with GPC (Tosoh, model HLC8020) using polystyrene standards in chloroform solvent. The columns were TSK gel G4000HXL and a TSK gel G3000HXL with a limited exclusion molecular weight of $4 \times 10^{5}$. The eluent was $\mathrm{CHCl}_{3}$ and the flow rate was 0.6 ml/min (Huh, 1999; Hyon, 1997). $\varepsilon$<smiles>CC1OC(=O)C(C)OC1=O</smiles>

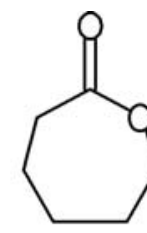

$\varepsilon$-Caprolactone

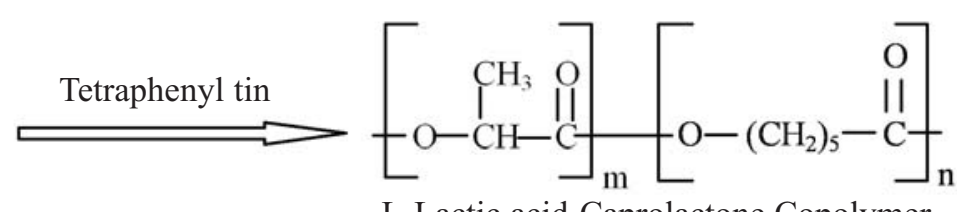

L-Lactic acid-Caprolactone Copolymer

Fig. 1: Polymerization scheeme 


\section{Thermal analysis}

The thermal behavior of the polyesters was studied by using a differential scanning calorimeter (DSC, model-10A) connected with a chart recorder and a temperature control unit (PTC 10D, Rigaku). The heating rate was $10^{\circ} \mathrm{C} / \mathrm{min}$ and an empty aluminum pan was used as reference. The glass transition temperature $\left(\mathrm{T}_{\mathrm{g}}\right)$ was determined as the lower flexion point of the recorded step change in heat capacity, and melting points $\left(\mathrm{T}_{\mathrm{m} 1}, \mathrm{~T}_{\mathrm{m} 2}\right)$ were defined as the peaks of the endotherm curve (Ljungberg, 2005; Kawasaki, 1998).

Samples of 3-8 $\mathrm{mg}$ (weighed into aluminum pans) were measured from $-50^{\circ} \mathrm{C}$ to $250^{\circ} \mathrm{C}$ at a heating rate of $10^{\circ} \mathrm{C} / \mathrm{min}$.

\section{Biodegradation}

The Biodegradability was evaluated in three different methods
a. Enzymatic hydrolysis test
b. Compost degradation test and
c. Activated Sludge test

\section{Enzymatic hydrolysis}

Polyester samples $(20 \pm 0.5 \mathrm{mg})$ and $5 \mathrm{ml}$ phosphate buffer $\left(\mathrm{NaH}_{2} \mathrm{PO}_{4} / \mathrm{Na}_{2} \mathrm{HPO}_{4}, \mathrm{pH}=7.00\right)$ were added to each of the four tubes. Then 100 units of eczyme Proteinase-K were added in to two of the each tubes and other two were for blank test. The test was carried out at $37^{\circ} \mathrm{C}$ for $24 \mathrm{~h}$. After filtration $(0.2 \mu \mathrm{m}$ membrane filter) TOC (total organic carbon) was measured. The TOC values were corrected appropriately by subtracting the blank levels ( $\mathrm{Li}, 1996$; Kawasaki, 1998).

\section{Compost degradation test}

The standard compost was supplied by the company. The moisture content of the compost is $63 \pm 2 \%$. A small piece of sample is kept at the centre of the compost in a digester and the digester is kept in a closed vessel with excess water so that its inside become saturated by moisture. Then the whole vessel is keept in an oven at $60^{\circ} \mathrm{C}$ for 15 days. Then the biodegradation is calculated by the percent weight loss (Karlsson, 1998).

\section{Activated Sludge test:}

In this test method the sample $(30 \pm 0.3 \mathrm{mg})$ is digested in Activated Sludge in a controlled buffer medium $\left(\mathrm{KH}_{2} \mathrm{PO}_{4}\right.$, $\mathrm{K}_{2} \mathrm{HPO}_{4}$, and $\mathrm{Na}_{2} \mathrm{HPO}_{4} \cdot 2 \mathrm{H}_{2} \mathrm{O} ; \mathrm{pH}=7.00$ and stabilizers $\mathrm{NH}_{4} \mathrm{Cl}, \mathrm{MgSO}_{4} \cdot 7 \mathrm{H}_{2} \mathrm{O}, \mathrm{CaCl}_{2}$ and $\mathrm{FeCl}_{2} \cdot 6 \mathrm{H}_{2} \mathrm{O}$ in distilled water). Activated Sludge and Buffer solution ratio in digester is $1: 10$. The test is carried out at $27^{\circ} \mathrm{C}$ for 60 days. The sample is digested to $\mathrm{CO}_{2}$, which is absorbed by $\mathrm{CaCl}_{2}$ as a result $\mathrm{O}_{2}$ is consumed inside the digester and Biodegradation is calculated from the $\mathrm{ml}$ of $\mathrm{O}_{2}$ consumed (Kawasaki, 1998).

\section{Results and Discussion}

\section{Synthesis and characterization of polymers and copoly-} mers

The homopolymers of L\&D-Lactic acid and $\varepsilon$-Caprolactone and copolymers of L-Lactic acid and $\varepsilon$-Caprolactone molar feed ratio 90:10, 50:50 and 10:90 were obtained by ringopening polymerization (ROP) reaction using Tetraphenyl tin as a catalyst. The product composition can be controlled by varying the feed ratio of monomers at a definite reaction

Table I: Polymerization reaction characteristics

\begin{tabular}{lcccccccc}
\hline Feed ratio & Product Composition & Catalyst & Temp. & Time $(\mathrm{H})$ & Yield & $\mathrm{M}_{\mathrm{n}}$ & $\mathrm{M}_{\mathrm{w}}$ & $\mathrm{M}_{\mathrm{w}} / \mathrm{M}_{\mathrm{n}}$ \\
\hline PLLA $=100$ & 100 & $\mathrm{Sn}(\mathrm{Ph})_{4}$ & 125 & 46 & 94.44 & 98781 & 141156 & 1.43 \\
PLLA $=100$ & 100 & $\mathrm{Sn}(\mathrm{Ph})_{4}$ & 135 & 72 & 96.82 & 106695 & 167824 & 1.57 \\
PDLA $=100$ & 100 & $\mathrm{Sn}(\mathrm{Ph})_{4}$ & 125 & 42 & 94.58 & 56186 & 67423 & 1.12 \\
PDLA $=100$ & 100 & $\mathrm{Sn}(\mathrm{Ph})_{4}$ & 140 & 62 & 98.35 & 90595 & 151294 & 1.67 \\
LA:CL=90:10 & $90.5 / 9.5$ & $\mathrm{Sn}(\mathrm{Ph})_{4}$ & 130 & 70 & 94.00 & 107929 & 158656 & 1.47 \\
LA:CL $=50: 50$ & $52.3 / 47.7$ & $\mathrm{Sn}(\mathrm{Ph})_{4}$ & 130 & 72 & 91.36 & 93110 & 131283 & 1.41 \\
LA:CL $=10: 90$ & $7.7 / 92.3$ & $\mathrm{Sn}(\mathrm{Ph})_{4}$ & 125 & 70 & 89.87 & 80536 & 110334 & 1.37 \\
PCL $=100$ & 100 & $\mathrm{Sn}(\mathrm{Ph})_{4}$ & 125 & 98 & 85.70 & 34292 & 60010 & 1.75 \\
\hline
\end{tabular}


condition. The polymerization reaction is highly temperature sensitive. Minimum $120^{\circ} \mathrm{C}$ temperature is required for obtaining a satisfactory lower molecular weight $\left(\mathrm{M}_{\mathrm{w}}-10,000\right.$ min.) polymer and $130-135^{\circ} \mathrm{C}$ temperature gives a satisfactory higher molecular weight $\left(\mathrm{M}_{\mathrm{w}}-1,50,000 \mathrm{~min}\right.$.) polymer. Temperature higher than $140^{\circ} \mathrm{C}$ shortens the reaction time by 12-24 hrs but yellowing of the product is occurred.

The effect of time in polymerization reaction is also significant. Low time gives lower molecular weight polymer and higher time gives higher, but very high time and temperature gives yellowing of the product and then burns. The polydispersity $\left(\mathrm{M}_{\mathrm{w}} / \mathrm{M}_{\mathrm{n}}\right)$ also depends on the temperature and time. At moderate temperature and time $\left(130-135^{\circ} \mathrm{C}\right.$ and $72 \mathrm{hr}$.) the polydispersity is satisfactory. At this temperature and time the product yields are also higher (around $85-95 \%$ ).

\section{Mechanical properties}

After formation of film, from the obtained polymers by solvent casting method in chloroform solvent, the tensile strength and elongation properties are observed. The higher molecular weight polymer shows higher tensile strength properties. Molecular weight doesn't show any influence in elongation properties. In presence of a small amount (about $10 \%$ ) of Caprolactone the L-Lactic acid and Caprolactone copolymers shows high tensile strength and very high elongation properties.
At very high amount (up to $90 \%$ ) of Caprolactone content, the tensile strength and elongation properties gradually decrease. At this composition the TS value is even less than pure PLLA but the elongation property is improved.

\section{Thermal properties}

From the Differential Scanning Calorimetry (DSC) analysis the melting temperature $\left(\mathrm{T}_{\mathrm{m}}\right)$ of PLLA and PDLA are around $180^{\circ} \mathrm{C}$ and $\Delta \mathrm{H}$ is around $50 \mathrm{~J}$, , but in case of second heating the $\mathrm{T}_{\mathrm{m}}$ is decreased slightly (by $5-10^{\circ} \mathrm{C}$ ). In case of PCL the $\mathrm{T}_{\mathrm{m}}$ is $67^{\circ} \mathrm{C}$ having no glass transition temperature $\left(\mathrm{T}_{\mathrm{g}}\right)$ and in second heating it is decreased to $56^{\circ} \mathrm{C}$, but another $\mathrm{Tm}$ value shows at $32^{\circ} \mathrm{C}$. The presence of caprolactone in PLLA copolymer, $\mathrm{T}_{\mathrm{m}}$ is decreased significantly and with the increase of its percentage the value decrease gradually. The presence of caprolactone in copolymer eliminates the $T_{g}$ of L-Lactic acid (Table II).

\section{Stereo-effect}

To study the stereoeffect of the obtained homopolymer (PLLA) and copolymers (PLLA:CL) the film of the blends were obtained by solvent casting method of dissolving the polymer and copolymers at a ratio of 50:50 (by wt.) in chloroform solvent.

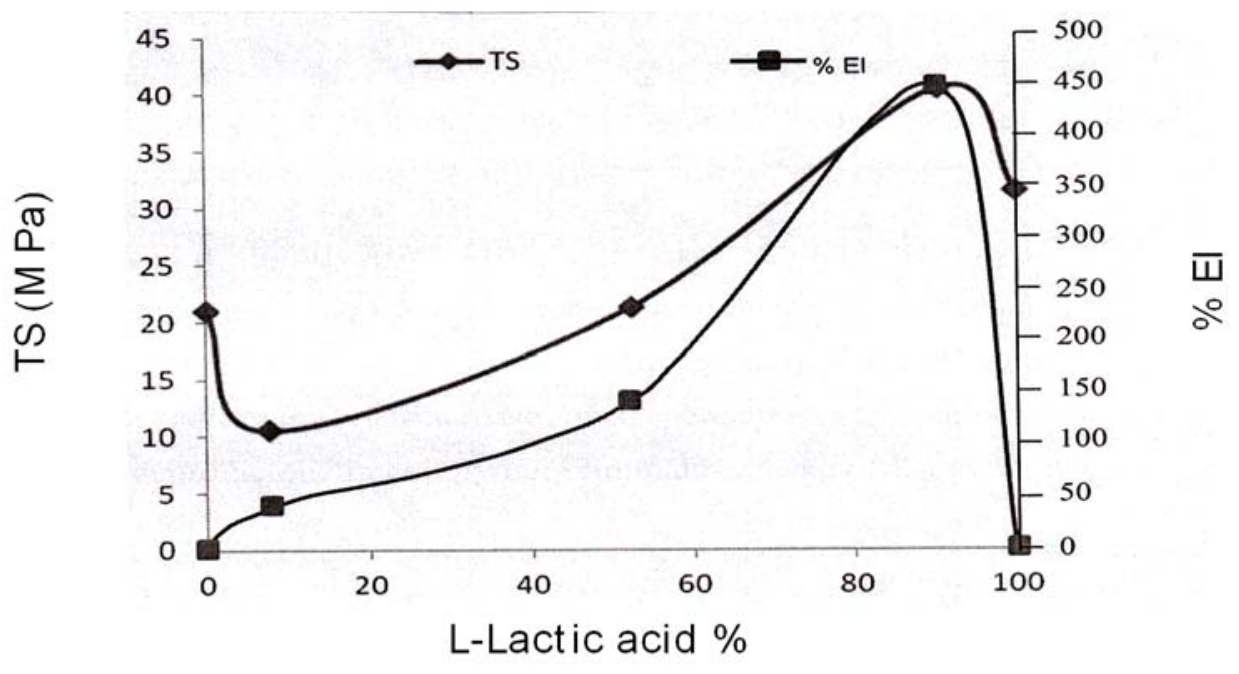

Fig. Tensile strength and elongation at break curve of polymers 
Table II: Thermomechanical properties of polymers and copolymers

\begin{tabular}{lccccccccc}
\hline $\begin{array}{l}\text { Product } \\
\text { Composition }\end{array}$ & $\mathrm{Mw}$ & $\mathrm{TS}$ & $\% \mathrm{El}$ & 1st Tg & 1st Tm & 1st $\Delta \mathrm{H}(\mathrm{J})$ & 2nd Tg & 2nd Tm & 2nd $\Delta \mathrm{H}(\mathrm{J})$ \\
\hline PLLA=100 & 141156 & 24.10 & 6.53 & 111.2 & 179.9 & 45.81 & - & 176.2 & 51.38 \\
PLLA=100 & 167824 & 31.44 & 6.47 & 112.1 & 179.8 & 51.12 & - & 176.1 & 56.33 \\
PDLA=100 & 67423 & 41.62 & 15.30 & 115.5 & 179.3 & 54.20 & - & 171.7 & 51.12 \\
PDLA=100 & 151294 & 45.38 & 15.40 & 116.2 & 179.8 & 52.23 & - & 171.3 & 47.18 \\
LA:CL=90.5/9.5 & 158656 & 40.45 & 450.47 & - & 151.2 & 13.19 & - & - & - \\
LA:CL=52.3/47.7 & 131283 & 21.23 & 145.73 & - & 148.3 & 12.67 & - & - & - \\
LA:CL=7.7/92.3 & 110334 & 10.51 & 44.67 & - & 142.7 & 12.45 & - & - & - \\
PCL=100 & 60010 & 21.86 & 11.50 & - & 67.4 & 89.95 & - & 31.7 & 62.77 \\
& & & & & & & & 55.9 & 65.78 \\
\hline
\end{tabular}

Table III: Stereo-effct of copolymers

\begin{tabular}{|c|c|c|c|c|c|c|c|c|c|}
\hline $\begin{array}{l}\text { Product } \\
\text { Composition }\end{array}$ & $\begin{array}{l}\text { Ratio with } \\
\text { PDLA }\end{array}$ & TS & $\% \mathrm{El}$ & $1 \mathrm{st} \mathrm{Tg}$ & $1 \mathrm{st} \mathrm{T}_{\mathrm{m}}$ & 1st $\Delta \mathrm{H}(\mathrm{J})$ & 2nd $T_{g}$ & $2 \mathrm{nd} \mathrm{T}_{\mathrm{m}}$ & 2nd $\Delta \mathrm{H}(\mathrm{J})$ \\
\hline PLLA $=100$ & $50-50$ & 60.86 & 104.73 & - & 237.6 & 65.06 & - & 232.8 & 86.31 \\
\hline $\mathrm{LA}: \mathrm{CL}=90.5 / 9.5$ & $50-50$ & 44.06 & 333.47 & - & 206.5 & 34.18 & - & - & - \\
\hline $\mathrm{LA}: \mathrm{CL}=52.3 / 47.7$ & $50-50$ & 22.58 & 123.62 & - & 206.2 & 26.81 & - & - & - \\
\hline $\mathrm{LA}: \mathrm{CL}=7.7 / 92.3$ & $50-50$ & 6.88 & 32.93 & - & 204.6 & 22.96 & - & - & - \\
\hline
\end{tabular}

From the DSC of the obtained blend films it is clear that the blends form stereocomplex perfectly at any composition of caprolactone in copolymer. The $\mathrm{T}_{\mathrm{m}}$ value increased by about $50^{\circ} \mathrm{C}$ in all cases but does not show second $\mathrm{T}_{\mathrm{m}}$. The tensile

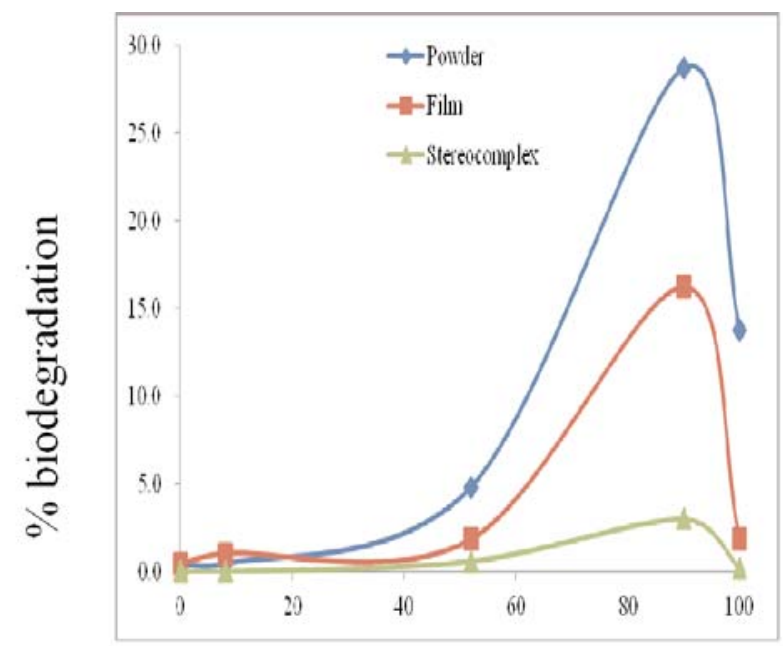

Lactic acid \%

Fig. Enzymatic biodegradation strength and percent elongation also increased significantly except TS at 90\% CL.

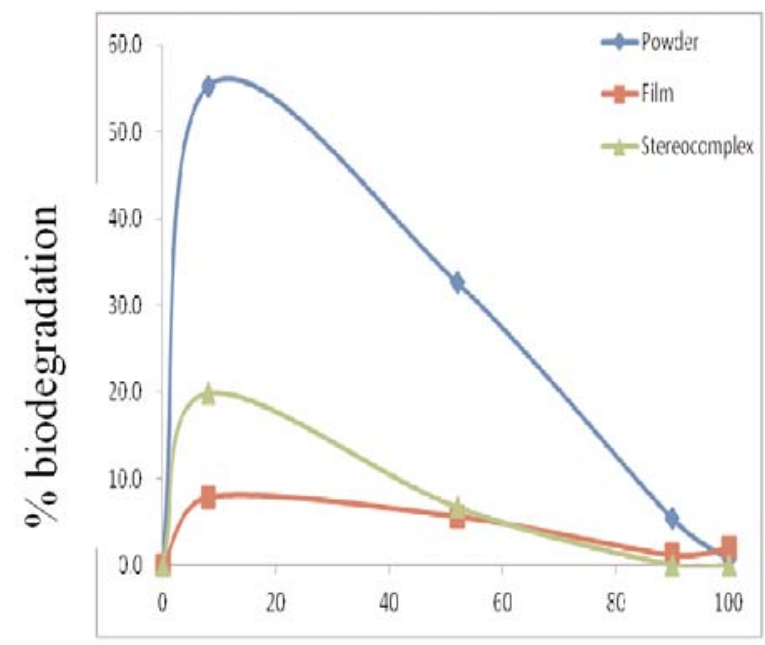

Lactic acid \%

Fig. Activated sludge biodegradation 


\section{Biodegradation}

In Enzymatic biodegradation the copolymer of ratio $\mathrm{LL}: \mathrm{CL}=90: 10$ shows highest biodegradation in all powder, film and stereocomplex forms. 90\% Lactic acid content copolymer shows highest biodegradation. Among the three forms the powder form shows highest biodegradation (about $30 \%$ in $24 \mathrm{hrs}$.) then film form (about 15\% in $24 \mathrm{hrs}$.) and the stereocomplex form is the least (about 3\% in $24 \mathrm{hrs}$.). With the increase of CL\% the value decreased gradually.

In case of Activated Sludge Biofegradation higher percentage of CL content copolymers show higher biodegradationin all three froms. 8\% Lactic acid containing copolymer shows the highest biodegradation. The powder form shows the highest biodegradation (about 55\% in 60days), then stereocomplex form (about 20\% in 60days) and then the film form is the least (about 3\% in 60days). With the increase of LA $\%$ the value decreased gradually.

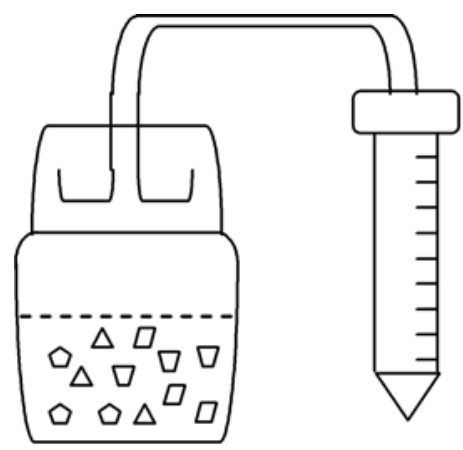

Fig. Activated sludge biofegradation

The Activated sludge and Compost Biodegradation method show similar biodegradation tendency because Caprolactone has higher biodegradation value than Lactic acid, but in case of Enzymatic method the result is reversed due to the fact that we used the enzyme that has high activity for poly lactic acid and poor activity for caprolactone.

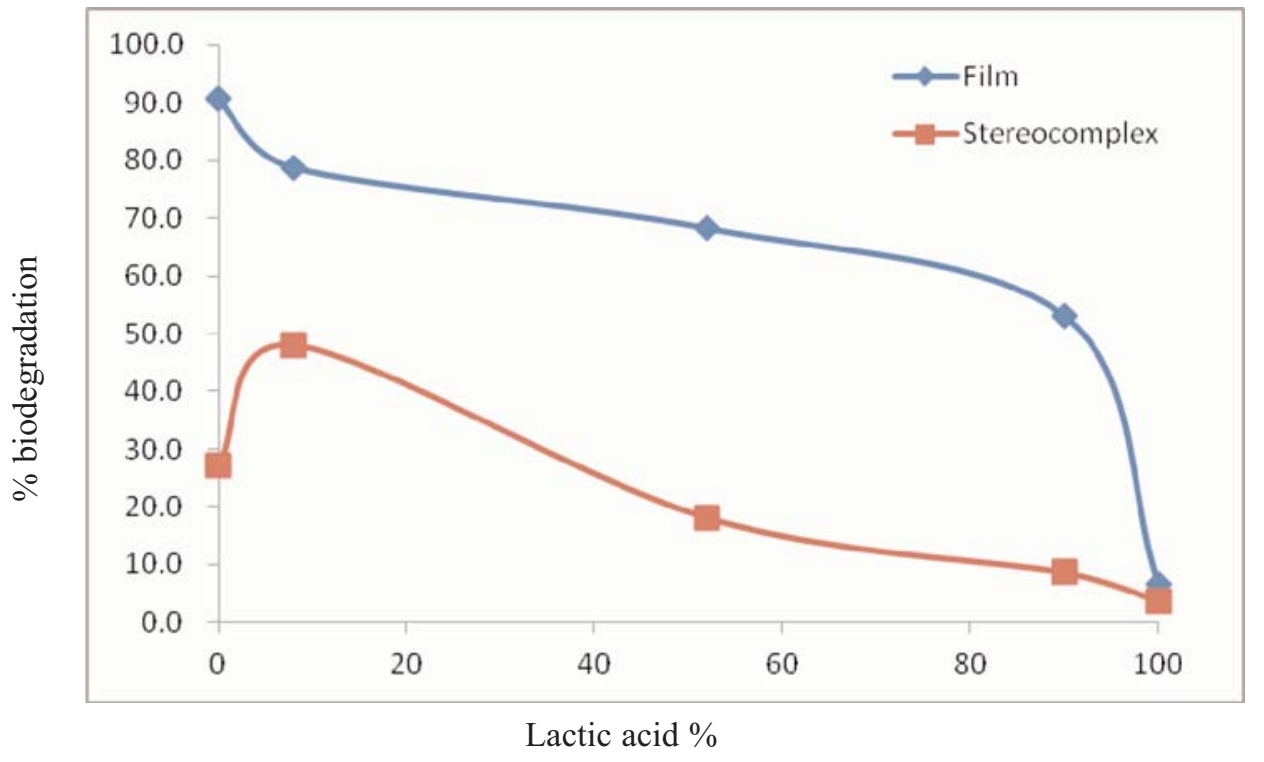

Fig. Composting biodegradation

In Compost Biodegradation method the degradation rate is increased first rapidly then gradually with the increase of CL percentage and pure PCL has the highest value (about 90\% in 15 days). The setreocomplexes also show steady and gradually increased biodegradation rate with the increase of caprolactone percentage. But the highest biodegradation value shows the copolymer of less lactic acid content, not any of the pure polymers.

\section{Conclusion}

Copoly(LLA/CL)s were synthesized from the two different kinds of monomers. One is biomonomer and another is nonbiomonomers both has biodegradibility. L-lactic acid, which can be produced from important bioresources, glucose and plant oil. These two monomers can be polymerized in any 
composition and composition can be controled by changing feed ratio. Copolymers containing less percentage of caprolactone show high mechanical and thermal properties. The mechanical and thermal properties also can be improved by the formation of stereocomplex and all the compositions of L-Lactic acid and caprolactone copolymers form stereocomplex with poly D-Lactic acid. The higher lactic acid content copolymers show high Enzymatic biodegradability because enzymes are very sensetive to compounds. On the other hand in Activated Sludge and Composting biodegradation methods show higher biodegradability at higher percentage of caprolactone containing copolymers. Because Activated Sludge and Compost provides versatile microorganism seeds at the test.

\section{References}

Avella M, Bonadies E and Martuscelli E 2001. European current standardization for plastic packaging recoverable through composting and biodegradation. Polymer testing. 20: 517-521.

Blair Coursey 2007. www.greenbiz.com/news/ 2007/05/03/ plastic-waste-more-dangerous-global-warming.

Bruno Gervet 2007. The use of crude oil in Plastic making contributes to Global Warming. Renewable Energy Research Group, Division of Architecture and Infrastructure, Luleå University of Technology, SE97187 Luleå, Sweden. www.ltu.se/cms_fs/1.5035! /plastics\%20-\%20final.pdf.

Courgneau C, Domenek S, Guinault A, Averous L and Ducruet L 2004. Analysis of the structure-properties relationships of different multiphase systems based on plasticized PLA, Journal of Polymers and the Environment. 19(No2):362-371.

Espartero JL, Rashkov I, Li S M, Manolova N and Vert M 1996. NMR analysis of polylactic acid macromolecules. Macomolecules. 59: 3535-3539.

Fritz J, Link U and Braun R 2001. Environmental Impacts of biobased/biodegradable Packaging. Starch. 53: 105109.
Hernandez RJ 2004. Handbook of Plastics, Elastomers, and Composites, Chapter-11 Plastics in Packaging.

Huh KM. and Bae YH 1999. Synthesis and characterization of poly (ethylene glycol)/poly (L-lactic acid) alternating multiblock copolymers. Polymer. 40: 6147-6155.

Hyon SH, Jamshidi Kand Ikada Y 1997. Synthesis of polylactides with different molecular weights. Biomaterials. 18(22): 1503-1508.

Karlsson RR, Albertsson A-C 1998. Biodegradable polymers and environmental interaction. Polymer Eng \& Sci. 38(8): 1251-1253.

Kawasaki N, Nakayama A, Maeda Y, Hayashi K, Yamamoto N and Aiba S 1998. Synthesis of a new biodegradable co polyester amide poly lactic acid co caprolactam. Macromolecular Chemistry and Physics. 199:24072415.

Kelly WE and Gupta A 1997. Polymer Laminations and Coatings Conference Proceedings, Toronto, 145-147.

Kylma J, Harkonen M and Seppala JV 1997. The modification of lactic acid based polymer by copolymerization. Journal of Applied Polymer Science. 63(13):18651872.

Leaversuch R 2002. Biodegradable polyesters; Packaging goes green, Plastics Technology, 48(9): 66-73.

Li SM, Rashkov I, Espartero JL, Manolova N and Vert M 1996. Synthesis, Characterization, and Hydrolytic Degradation of PLA/PEO/PLA Triblock Copolymers with Long Poly(L-lactic acid) Blocks. Macromolecule. 29: 57-62.

Ljungberg N, Colombini D and Wessle'n BJ 2005. Plasticization of poly (lactic acid) with oligomeric malonate esteramides: Dynamic mechanical and thermal film properties. Appl Polym Sci. 96(4): 992-1002.

Luc Averous. 2009. www.biodeg.net/bioplastic.html, Biodegradable polyesters (PLA, PHA, PCL.....). 
Maneka G 2010. Major Environment Problems; Articles in People for Animals-India's largest Animal welfare organization. 23-53.

Nadia Ljungberg and Bengt Wesslén. 2003. Tributyl citrate oligomers as plasticizers for poly (lactic acid): thermomechanical film properties and aging. Science Direct. www.sciencedirect.com/science/article/pii/S00323861 03008954.

Nijenhuis AJ, Grijpma DW and Pennings AJ 1992. Lewis acid catalyzed polymerisation of L-lactide. Kinetics and mechanism of esters of bulk polymerisation. Macromolecules. 25(24): 6419-6424.

Pitet LM, Hait SB, Lanyk TJ and Knauss DM 2007. Linear and Branched Architectures from the Polymerization of Lactide with Glycidol. Macromolecules. 40: 23272334.
Sinclair RG 1995. The case for polylactic acid as a commodity packaging plastic. Polym. Mater. Sci. Eng. 72: 133-5.

Tasaka F, Ohya Y and Ouchi T 2001. One-Pot Synthesis of Novel Branched Polylactide Through the Copolymerization of Lactide with Mevalonolactone. Macromol Rapid Commun. 22: 820-824.

Woo SI, Kim BO, Jun HS and Chang HSN 1995. Polymerization of lactic acid to prepare high molecular weight poly lactic acid by chain extending and hexamethylene diisocyanate. Polymer bulletin. 35(4):415421 .

Yoshiharu K 2009. Design of Bio-Based Polymers: Molecular, Structural and Material Design of BioBased Polymers, Polymer Journal. 41: 797-8073.

Manuscript received on 01 December 2011; revised on 08 February 2012; accepted on 26 Februaryr 2012 